\title{
Baukultur in a Cybernetic Age: A Conversation
}

\author{
Michael A. Arbib, Meredith Banasiak, Bob Condia, \\ Colin Ellard, Jonathan Enns, Melissa Farling, \\ Robert Lamb Hart, Richard Hassell, \\ Eduardo Macagno, Harry Mallgrave, Fred Marks, \\ Juhani Pallasmaa, and Sarah Robinson
}

CROSS-DISCIPLINARY STUDIES

We received and we gladly publish this conversation among distinguished theorists and scholars on an important topic, also aligned with the cross-disciplinary mission of our journal. [MS]

ABSTRACT - The article offers a multi-author conversation charting the future of architecture in light of the apparent tension between Baukultur, which combines the culture of building and the building of this culture, and the rapid changes brought about by digital technology, embracing cybernetics and artificial intelligence. The article builds on a discussion of Baukultur to debate in what sense buildings are "machines for living in," then examines neuromorphic architecture wherein cybernetic mechanisms help buildings sense the needs of their occupants. It closes with an example of a building complex, Kampung Admiralty, that combines cybernetic opportunities with a pioneering approach to building "community and biophilia" into our cities. This article interleaves an abridged version of Michael Arbib's (2019) article "Baukultur in a Cybernetic Age," " with extensive comments by the co-authors.

Keywords: artificial intelligence, Baukultur, biophilia, cybernetics, neuromorphic

Arbib: The 2018 Davos Declaration "highlights pathways for Politically and strategically promoting the concept of a high-quality Baukultur in Europe" 2 emphasizes both a society's particular "culture of building" (how they go 
about creating their built environments) and the "building of this culture" (how the quality of what they do and what they produce can be raised).

\section{BAUKULTUR - A GLOBAL CHALLENGE}

Ellard: One of my base beliefs about Baukultur is that the traditional building practices had high-quality Baukultur built into them, and that a big part of the problem with modern design has been the freedom afforded by modern materials to depart from these practices.

Hassell: One problem with the desire to build in a traditional timeless way is that, actually, there has been no such thing. The accelerating change in the size of settlements over millennia required using the latest technology. Going vertical, fire safety, infrastructure, waste are problems stones and timber cannot solve.

Arbib: We can add a political dimension (factory owners packing their workers into the cheapest possible housing nearby) and cultural ones (e.g., treatment of men versus women). Another issue is the transition from traditional symbolism - a church looks like a church - to modern constructions that avoid such symbolism.

Farling: Richard Buday states, "For thousands of years, architects were the world's storytellers, making architecture a great book of humanity, shaping societies in ways today's buildings do not. Humans are meaningseeking animals ... Until the Late Middle Ages, architecture was a dominant storytelling medium, which gave architects the persuasive power to change what people thought and what they did." ${ }^{3}$

"World Building," as developed in designing settings for movies like Minority Report, may offer new clues for architecture, by engaging multiple stakeholders to prototype a vision of ways that realize the technological, environmental and economic aspirations of a project. By providing "voice" to the stories, culture is able to be embedded in design.

Pallasmaa: We are living in a culture of extremely rapid and fundamental changes. The new technologies tend to distance us from the material, mental and social realities and eventually turn our life world into entertainment and games. In my view, the mental task of architecture is to strengthen our reality sense, and at the same time, to defend the autonomy and authenticity of the human experience.

From its very beginning, architecture has mediated between us humans and the world, but this essential mediating task has been all but lost. The architectural profession is turning into a service profession like engineering and lawyering, satisfying the desires of investors or the need of cultural institutions for memorable architectural images to serve purposes of visibility and identity. Architecture needs to mediate true experiences of the world, our selves, and human existence.

Hart: Architects generally dismiss the idea that codes, the science they're based on, and the government entities that enforce them, have much to do with culture, arguing that codes are negative, that our culture emerges out 
of their own creativity. However, the alternating teamwork and bitter battles of politically supported building approval processes are an integral part of shaping each generation's cultural legacy.

Arbib: Two challenges (among many) as to the nature of a society's "culture": 1) A society's culture is dynamic.

When the Eiffel Tower was opened in 1889, many deemed it a World's Fair gimmick that would, hopefully, be demolished after the Fair. Yet today it persists as a Paris icon. In the 1880s, then, was the Eiffel Tower an affront to French culture or a powerful symbol of a culture open to technological change? Notre-Dame de Paris holds the memory of a great period of pan-European Christian culture. It was drastically damaged by fire on April 16,2019 . Yet one does not have to be French or Christian to mourn this catastrophe. Both this 800-year-old cathedral and the 100-year-old Eiffel Tower have become integral to our pan-cultural sense of Paris.

2) The diversity of cultures even within a single region.

In Europe today, is a mosque a symbol of cultural breadth or a stimulus for hatred? The challenge for Baukultur is to support historical memory as well as healthy modern living, with cultural complexity honoring both unity and diversity.

Black churches burned in the southern US; Christian churches bombed in Sri Lanka; the individual turned into an almost faceless "one of them." Baukultur seems a lot more complex than the Davos Declaration lets on. Banasiak: Social psychologists are working to understand the underlying neural responses between members of intergroup conflicts. ${ }^{4}$ The suggestion that artifactual stimuli representing a culture can induce a similar response in someone from an opposing group is worth exploring. Studies on the effect of imagery on trauma-related symptoms of war veterans ${ }^{5}$ might well inform artifact-based therapeutic applications to mitigate racism and intergroup conflict.

Mallgrave: Politicians in the Great Society programs believed that they could eliminate poverty within a decade with their Model Cities programs, but never tackled the issues of mental health or public education.

Architecture is simply building, and it is not some semiotic code that alters peoples' behavior. It is more radically a multisensory and emotional experience that, when done well, makes people happy rather than angry. It should respond to the issue of "how" we live.

Arbib: I suggest that we need to develop for Baukultur the European Union's "principle of subsidiarity," namely that a central authority should have a subsidiary function, performing only those tasks which cannot be performed effectively at a more immediate or local level. But how then does one preserve a pan-union cultural matrix that respects various component cultures?

In Belfast, the "peace walls" remain in many parts of the city, with Protestant enclaves on one side and Roman Catholic on the other, expressing and preserving distrust between the two cultures. Some residents have resumed visits to the areas of the "others," yet some still seek to maintain 
a culture of hostility - a confrontation of an architectural "solution" with the enduring passions of those who reject a culture of co-existence.

There is only so much architecture can do. Time and again, demagogues can re-awaken dormant hatreds and invent new grievances at the expense of the "other." To the extent that it can provide a counterweight, the issue for architecture is one of subsidiarity and openness - there must be places special to each culture and yet they must be embedded in a larger system where each can understand the other and share certain values. Subsidiarity is a balancing act rather than an algorithm.

Farling: The area of the recent land port of entry at Nogales on the Arizona/ Mexico border is referred to as "ambos Nogales" or "both Nogales" embracing both sides of the border. The design of the land port of entry balances security and welcoming, while reflecting the culture that crosses the border as well as the more distinct cultures on each side. It is important to allow all of this to coexist.

Hassell: In Singapore, we are culturally attuned to assess what one group may find offensive, or what favors another group too strongly. For Chinese, some elements might resemble joss sticks and are avoided, while mosquelike elements used in a secular building might cause offence to Malays. For countries with a dominant culture which is starting to become more diverse, it is a matter of learning to understand other viewpoints and then learning ways of adapting to avoid causing offense.

Marks: If the rich lived next door to the poor, there would be a clearer understanding of inequality and a motivation to raise the standards for the have-nots. Thoughtful design should be accessible to everyone regardless of a project's scale. More money is not necessarily the answer. A pathway needs to exist for applying good ideas about aesthetics, social habitation and science, without unfair influence by the private sector and a governing party.

Arbib: Unfortunately, awareness of inequality need not yield a motivation to raise the standards for the have-nots. Awareness of social differences leads to US police forces being paid to protect "us" and subjugate "them." Again, the US funds schools with local property taxes, thus amplifying localized poverty with poor education. It takes political will to create the circumstances in which architecture can contribute.

Condia: Kenneth Frampton ${ }^{6}$ recognized that the onslaught of globalization was endemic, prompting him to call for an architecture of resistance, critical regionalism, based on a close reading of a place and culture. Such place making, expressed in modern city making, seems more important than ever, but people now spend $90 \%$ of their time inside buildings and, when outside, many spend much of this time tuned to social media. One obvious example of our being untethered from real places is the tribalism emerging on social media. This suggests that Baukultur is now more important than ever.

Hassell: Climate is to me a very strong driver of local design, as the local climate is common across different cultures co-existing in the same place. 
While we may have different symbolic readings of buildings, we all feel hot, cold or uncomfortable together.

Hart: A concept like Baukultur is always stimulating when taken seriously by people who have the resources and/or authority to actually build what the rest of us draw or talk about. What is spelled out as a Baukultur will not truly be our culture unless it's what the people who build (such as the developers and governments) are prepared to do in practice. Otherwise, it is one more interesting utopia. Diverse, contending interests range from investors and their architects to businesses with affected property holdings, and residents. The result: development policies are put in place by "political" decisions. The Davos Declaration's (Article 16) "all relevant disciplines and professionals must take part on an equal footing" is not likely to happen, as power hierarchies define their own interests in a political action.

\section{REVISITING THE SLOGAN "A HOUSE IS A MACHINE FOR LIVING IN"}

Arbib: The original essay explored Le Corbusier's "A House is a Machine for Living In," and included analysis of Le Corbusier's enthusiasm ${ }^{7}$ for both the engineer's and the architect's aesthetic. This discussion is abridged here.

Le Corbusier's inspiration came from three classes of machines: ocean liners, airplanes, and automobiles. "The airplane is the product of close selection. The lesson of the airplane lies in the logic which governed the statement of the problem and its realization." ${ }^{8}$ For him, the form follows once one states that "an airplane is a machine for flying in." 9

The problem of the house has not yet been stated. Nevertheless, there do exist standards for the dwelling-house. Machinery contains in itself the factor of economy, which makes for selection. "The house is a machine for living in." ${ }^{10} \ldots$ we shall arrive at the "HouseMachine," the mass-production house, healthy (and morally so too) and beautiful in the same way that the working tools and instruments which accompany our existence are beautiful. ${ }^{11}$

However, engineering aesthetics does not rule the heart of the architect Le Corbusier, for he makes the apparently contrary assertion that,

The business of Architecture is to establish emotional relationships by means of raw materials. Architecture goes beyond utilitarian needs. Architecture is a plastic thing. The spirit of order, a unity of intention. The sense of relationships; architecture deals with quantities. Passion can create drama out of inert stone. ${ }^{12}$

The Parthenon provides Le Corbusier's ideal of the architectural aesthetic. We can happily embrace the challenge of combining the engineering aesthetic (function smoothly achieved) and the architecture aesthetic (touching the emotions). Returning to the house, Le Corbusier asserts, 
The plan of the house, its cubic mass and its surfaces have been dictated partly by the utilitarian demands of the problem, and partly by imagination ... the architect has worked plastically; he has restrained utilitarian demands in deference to the plastic aim he was pursuing; he has made a composition. ${ }^{13}$

In short, "a building is a machine for X" cannot yield architecture for Le Corbusier unless the architect bends the demands of those utilitarian functions $X$ of the kind he stressed for ocean liners, airplanes, and automobiles to yield a "composition" - presumably using the word as one would for a symphony or a painting.

Ellard: Le Corbusier meant that as well as there being machines that were efficient in the sense of having the laundry in the right place for the maid there was also a sense in which a building could be an emotional machine. At one point he calls the Parthenon "a machine for stirring emotion." ${ }^{14}$ I would argue that there is science that can help predict the emotional impact of a piece of architecture and that we should use it.

Condia: Many architects know the machine analogy has lost its shine but haven't discovered, as we have at ANFA (the Academy of Neuroscience for Architecture, http://anfarch.org), that utilitarian functions may be better assessed in terms of "affordances" ${ }^{15}$ which refer to what we can (as humans) do with something in a particular place and atmosphere - like a rocking chair on a porch. These co-influences of our interaction with things and spaces lead me to suggest that affordances provide a "second skin for living." Le Corbusier's houses of the 1920s turn the traditional bearing wall tradition inside out, offering instead open floors divided by furnishings, abundant light, cross ventilation, views of the horizon, hygienic surfaces, and porches organized by the architectural promenade.

Farling: Beyond an engineering aesthetic, we need to understand how aesthetic pleasures are determined and (certainly consistent with ANFA's concerns) explore the role of memory, perception, empathy, and discovery in connecting to place, people, landscape, etc. Le Corbusier's machine for living does consider the "living" - the human experience of what we build.

Enns: For me, Le Corbusier is sort of "anti-Baukultur," representing an avant-garde method of practice that is less about a careful representation of shared values and cultural Zeitgeist and more of an excited revolution of new materials and a skilled manipulation of social arrangements.

Hassell: I do not find it so much anti-Baukultur as a radical querying of what Baukultur should be. If architecture at some basic level reflects our understanding of the cosmos and our place in it, then it needs to change as our understanding changes. But there is a huge inertia in the constructed environment, which is filled with representation of previous understandings, so occasionally it is necessary for someone to shrug off a lot of the previous representation to give space for a fresh expression of our new understanding. There is comfort in continuity, but it can also be a trap where we live our lives in the built expression of cognitive frameworks which are no longer relevant. 
Pallasmaa: Le Corbusier was a contradictory architect/artist. He defined the house enthusiastically as a machine to live in, but yet, his houses and buildings convey touchingly optimistic existential feelings and lived meanings.

Hart: We need new words that express the idea that aesthetic experience can be stirred by essentially all human artifacts (as well as nature) -fine materials and workmanship, fitness to purpose, "function smoothly achieved," sophisticated cybernetic systems that support other "functions" that building a place was intended to satisfy. Rather than opposing an engineering aesthetic and architecture aesthetic, it seems to me more productive to think of the evolved human capacity for aesthetic pleasure in terms of "a composition," but one incorporating more of the factors that we now know have influenced the design. Then in the design process, we would resolve the "form" of the functions and the "function" of the forms, as they are in a "beautiful" ship or in that extraordinary machine for worship, the Parthenon. A "composing," creative mind, like Le Corbusier, enlarges the ways we think about architecture, as Beethoven did with symphonies, and by both writing and performing, followed by imitation and controversy, becomes a living part of our dynamic Baukultur's ongoing evolution, for better or worse.

\section{A HOUSE IS A CYBERNETIC MACHINE/ROBOT/EMBRAINED BODY FOR LIVING IN}

Arbib: In this essay, "cybernetics" is an umbrella term that links brain research, neural networks, artificial intelligence (Al), computer networks, and robotics - whether applied to animals, humans or machines as multilevel, adaptive, embodied systems interacting with the world about them. Exploring how cybernetics may affect the nature of future buildings will address, in part, a motivating issue from Davos:

The fourth industrial revolution has begun. The vision of interconnectedness between virtual and physical devices in a global network, the "Internet of Things" (IOT), is becoming fact. ... This may have a growing impact on our physical environment: Cultural values, such as the authenticity and historic originality of material and substance, may lose importance in favor of more standardized images and perceptions. ${ }^{16}$

Neuromorphic Architecture ${ }^{17}$ studies buildings which "in some sense" have "brains," combining a (possibly dynamic) physical space with a "neural" space that controls its interactions. We may view such a building as an inside-out robot or an embrained body. Form and space of the building are "interactive," intertwined with actions and events, and even emotions, in the life of its users.

Neuromorphic Architecture exploits insights from "neuroethology" - the study of how brains of diverse animals control their behavior - that yield 
Brain Operating Principles in making the room (building, city, ...) more "interactive." I propose that careful attention to "neural space" (the "brain" or "interactive infrastructure," including sensors and effectors and their cybernetic integration) prior to commitment to the final form of the "physical space" will in future yield innovative designs enriched through constraint satisfaction between the physical and neural dimensions. Figure 1 aligns a schematic of the relation between the posited neural space of a building and its physical space with the brain and body of a distinctive creature, the star-nosed mole (Catania and Kass, 1996) (Fig. 1).

A building becomes a "system of systems" planned and constructed to address certain functionalities and yet which may combine and extend them to convey impressions, feelings, and aesthetic qualities. These buildings will vary from typology to typology as "machines" for efficiently supporting relevant functions $X, Y$ and $Z$ while offering aesthetic pleasures. "Intelligent" spaces will adjust to changing circumstances. We already have dynamic control of lighting and temperature (and the thermostat is an exemplary cybernetic system). In the longer term, these spaces will anticipate human activities and play an interactive role. Dynamic architectural settings using new materials will be able to learn and adapt over time. The structure and operation of buildings will increasingly become dynamically reconfigurable, ${ }^{18}$ while perceiving robots will serve as active furniture.

Hewitt: As Louis I. Kahn said, a building is "a society of rooms." ${ }^{19}$ Space Syntax in London, https://spacesyntax.com, uses algorithms to test the way adjacencies in the city influence things like traffic patterns, land use, and linked social functions.

Arbib: Will the advantages of cybernetics be outweighed by the invasion of privacy as personal data become increasingly accessible across the internet? Perhaps the principle of subsidiarity may again provide the framework for the search for solutions. At present, we download apps to our smart devices with no clear documentation on what the app can disseminate or its susceptibility to external influences. In future, it will be necessary for all devices to have clear documentation that allows informed control by each user of these options, with default settings that nudge ${ }^{20}$ the user toward privacy, rather than being pre-set to serve the interests of governments or corporations.

Condia: Corporations may do things we don't want - e.g., tracking where our phone has been. ${ }^{21}$ We expect our home to be a private, not a public, space - not just a place for social media. When you read a book, "you are exploring a world, it's not exploring you." 22

Mallgrave: what happens when the government decides it will control your lighting and temperature? How will this affect people who have very different metabolic rates and sensitivities to heat/cold? Neuromorphics is a fascinating idea, but the danger is that of control. Who controls whom? As a counterpoint to this, the central theme of the book I am presently writing is the idea of paradise, historically the garden, but the garden can also be defined in other creative ways. 


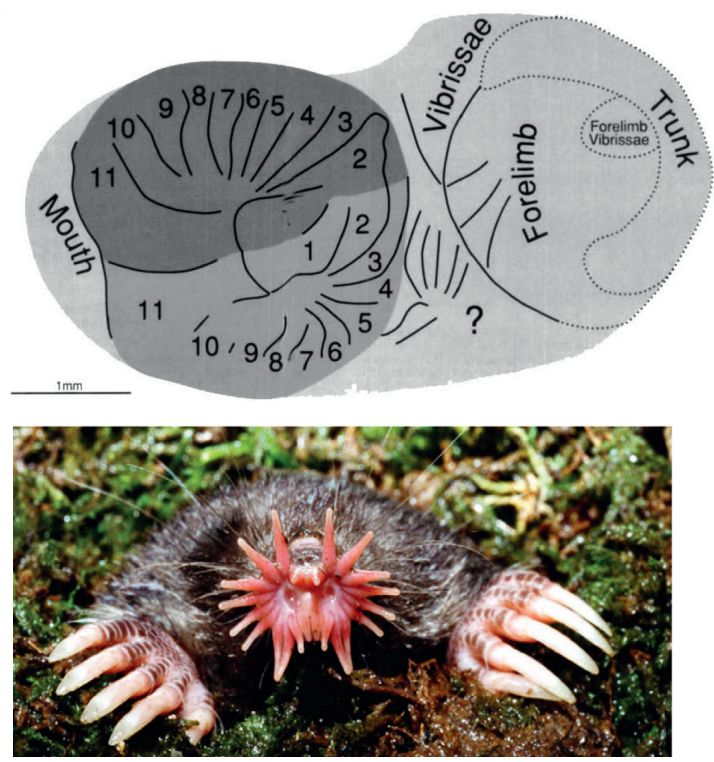

Neural space: sensor, neurally inspired interaction infrastructure, and effectors information flow here supports the dynamic interaction of the building with its inhabitants

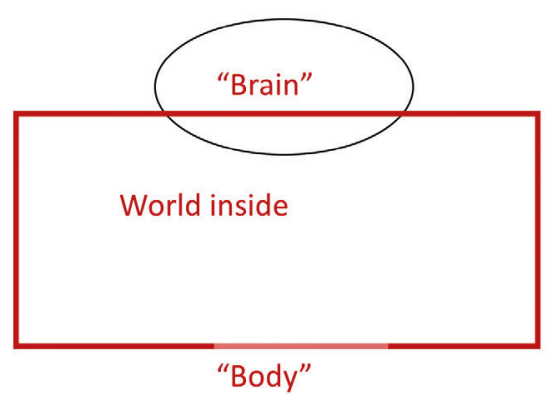

Physical space: the "standard" architectural challenge, combining function and aesthetics

Figure 1. (Left) Somatosensory cortex and body of a star-nosed mole, showing the way in which neural circuitry is dedicated to each "finger" of the star-nose chemo-tactile organ. (Right) Neural space ("brain") and physical space ("body") as two interacting spaces in a room or building. Information flow in the "neural space" supports the dynamic interaction of the building with its inhabitants and wider environment.

Arbib: There are real concerns here, but a key notion is that $\mathrm{Al}$ and the Internet of Things (IOT) can also provide individual adjustment for people who have very different metabolic rates and sensitivities to heat/cold, or who are aged, or who are blind or have other disabilities. Talking of gardens, note that the last section of this paper brings in the notion of biophilia.

Hassell: For me, simple things like public transport apps which calculate routes and tell you buses are arriving has transformed the way I use the city - I got rid of my car! For people with disabilities, Augmented Reality (AR) will be transforming. Tactile markers, canes and beeping traffic lights are incredibly crude means to help people with different abilities to navigate the world. I am sure relevant AR devices are already developed; there is only the hard infrastructure needed to support this, such as RFID tags built into everything to provide information at a high enough resolution. Robots with enough onboard processing to navigate visually in combination with data overlays could make this strategy obsolete very quickly. Infrastructural hardware is slow and expensive compared to personal device evolution.

Arbib: One important function of the autonomic nervous system is "homeostasis": Brains keep critical bodily variables in the range for survival. Jean Nouvel's Institut du Monde Arabe in Paris employed a wall of lightsensitive diaphragms to control the impact of sunlight on the space within, and is aesthetically pleasing in appearance. The downside was that the vast array of intricate machines was subject to breakdowns on such a scale that expensive rebuilding was needed. This provides both inspiration and a cautionary tale for future development of cybernetically reconfigurable architecture. 
Banasiak: Recent attempts to integrate the Internet of Things (IoT) into some of our healthcare projects have been challenging precisely because of such breakdowns. Moreover, sensors, controls, effectors are often developed by different manufacturers resulting in a Tower of Babel-like communication failure when wired together. Self-contained networks of adaptive systems from one purveyor like Google seem to circumvent this effect. However, such monopolies present a different set of cautionary drawbacks.

Arbib: Turning to "social interaction," a classic example is provided by the neuromorphic design of the interactive space "Ada" by a team led by computational neuroscientists Rodney Douglas and Paul Verschure. ${ }^{23}$ Ada attracted over 550,000 visitors at the 2002 Swiss National Exhibition. Ada was an "entertainment space" for visitors passing through, not a building for "serious" occupancy. Ada was constructed as a perceiving, acting and adapting entity. "She" had a "brain" based (in part) on artificial neural networks; she had "emotions" and "wanted" to play with her visitors. Ada used vision, audition and touch to locate and "identify" visitors. Her effectors allowed her to provide cues to visitors and express her internal states in an emotional "language" of vision and robotically composed sound. Hexagonal floor tiles could sense the motions of visitors but could also change colors to attract visitors to move together to form groups with whom she could interact (Fig. 2).

Hassell: We are currently working on a leisure attraction where guest preferences will be logged in before entering and their augmented reality experience is customized to this. The mental bubble becomes the physical bubble, where a person does not encounter things outside their preferences, and where two different people would come away from the place having had completely different experiences. It is both exciting and terrifying to imagine how this might spread to the real world.

Arbib: One concern is that buildings that engage in dynamic social interaction may respond in untoward ways, as exemplified in the 1962 story "The Thousand Dreams of Stellavista" by J.G. Ballard when its "psychotropic" houses run amok. ${ }^{24}$ The story turns on the conceit that houses may behave in ways that strongly, even alarmingly, express the emotional states of long-gone inhabitants rather than responding to the immediate needs of the current inhabitants. Ballard's (fictional) psychotropic houses reflect the emotions of their inhabitants, rather than helpfully responding to them. A further problem is that their expression of these emotions can last for years and have distressing expression in the dynamics of the house - a building with post-traumatic stress disorder. A fuller exposition of Ada is contained in "Brains, Machines and Buildings" 25 which also introduces three examples of Neuromorphic Architecture. Developed by computer science students at USC, they offered only rudimentary sketches for the "physical space" but focused on simulation of different components of the "neural space," based where possible on what 


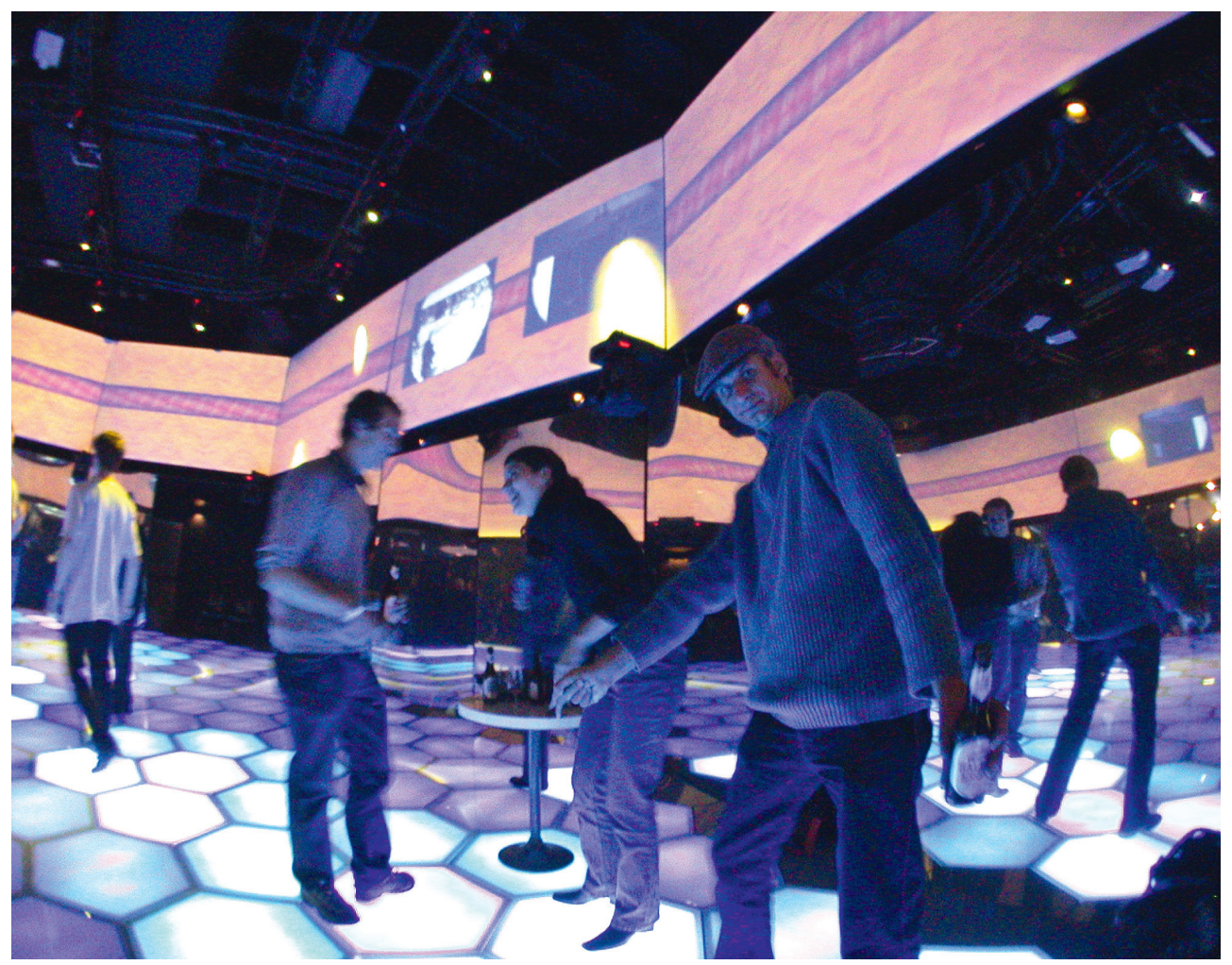

Figure 2. People interacting within and with the interactive space Ada.

the students had learned about modeling subsystems of animal brains. One group developed an "intelligent" kitchen which monitors and assists a human's food preparation. Its "brain" included a subsystem based on mirror neurons (working with systems "beyond the mirror") for action recognition. "Adaptation" and "learning" were at the heart of the conceptual design. A skillful chef would not want a kitchen like this, and even a novice cook could become frustrated by a kitchen that kept offering suggestions for routines that the cook had by now mastered. Two factors then enter. One is to use facial and vocal cues to recognize the "emotional state" of the user. Do they indicate frustration with excessive instruction or a measure of desperation in preparing the current dish? The room should be able to react accordingly. And this leads into "learning" - about both what the user can handle without assistance and where help is needed (and this changes over time), as well as how the user chooses to modify the recipe so that the room can keep track of the user's preferences. Moreover, we suggested as a future extension the restructuring of physical space to adapt over time and be reconfigurable to the needs of different users.

Farling: Might a Neuromorphic kitchen that keeps track of the users' preferences limit the creativity or serendipity that can happen? The goal of the ANFA Workshop: "Understanding the Cognitive Process of Neuroscientists at Work" held in May 2006 was to identify key characteristics of the work of neuroscientists and propose hypotheses 
linking the neuronal and architectural aspects of the spaces used in a laboratory facility. ${ }^{26}$ I think of the kitchen as a lab in the home. However, it is more than a space to simply make food, it is a space to experiment, to create, to connect to family, friends, memories. I have photos of my grandparents in my kitchen because they taught me how to cook, and the images trigger wonderful memories of my heritage and also give me confidence to be creative. Neuromorphic Architecture may be able to learn and even show emotion, but it also has to be able to share feeling for true empathy.

Hewitt: The mirror neuron system (and its partners beyond the mirror) offers a mechanism connecting humans to the animals (and fellow humans) with whom they interact.

Arbib: Stewart Brand focused on How Buildings Learn: What happens after They're Built. ${ }^{27}$ For Brand, humans provided the brains to adapt buildings for new uses. We ask how Neuromorphic Architecture may exploit insights into neural learning mechanisms to yield buildings that learn to adapt to the changing needs of users. Hopefully, the building will ask us before it makes the drastic changes ...

Banasiak: Google had an installation called "A Space for Being: Exploring Design's Impact on Our Biology" at the 2019 Milan Furniture Fair that explored neuroaesthetics - the study of the brain's response to aesthetic experience. ${ }^{28}$ Monitoring physiological response to discrete environmental variables and layering multiple sensory variables to understand their combined, cumulative effect is a first step toward programming buildings which can autonomously adapt to achieve a desired physiological state. Such ubiquitous monitoring, however, will require ethical standards ensuring the privacy of personal data.

Juhan Sonin argued for a smart bathroom, as a machine for monitoring and thereby optimizing health. ${ }^{29}$ Our health and drive toward longevity may be just the advantage which outweighs privacy. Big data, if used ethically, would increase our health status awareness and our access to diagnostic information faster and more accurately than our current healthcare system. Farling: Hospitals provide one typology where biology-based design is important - a hospital may be envisioned as a machine for healing. A very different typology is offered by prisons and jails. Since the early 1970's, best practice in US prisons and jails used direct supervision by guards stationed within a housing unit in an effort to provide a safer and less stressful environment, rather than isolated monitoring of video cameras. The effectiveness of direct supervision has been documented by architects and environmental psychologist. ${ }^{30}$ However, there is not much effort to minimize all use of video surveillance because the presence of cameras is considered part of the deterrence. A prison can be seen as a machine for warehousing or rehabilitation depending on the location and the philosophy of the community.

Condia: In my lifetime, places like Venice have "evolved" from historic cities into stops on the cruise ship circuit, where experience is reduced to snapshots to be shared on-line. In resistance to this onslaught of numbing 
commercialization, an architecture informed by neuroscience suggests that the real is a brain/body's multimodal sensory and motor co-habitation with spaces understood as a human biology or ecology. "Machine" in this regard is understood as an extension of potential actions by tools, within one's peripersonal space as extended by the machine. But will Al help individuals feel more at home? We refer to home by its stability and familiarity, yet the notion remains action-oriented - to be at home is what we do there. When Al conforms to your whims in advance, after the novelty, what is left for human interaction? Is Al manifestly an anti-affordance?

Ellard: I am worried about what Albert Borgmann ${ }^{31}$ calls the "device paradigm" where technology that ostensibly provides a cocoon of comfort ends up detaching us from our environment and from each other (one simple example is again the thermostat and central heating, which free us from chopping wood, watching the weather, etc. - some might say happily so, but still there are costs). I imagine the cocooning effect writ large with sensors for my physiological and emotional state and the impact that might have. We like our technology and most of the time it makes life easier, but every time that happens there is a loss.

Pallasmaa: Reyner Banham's (1965) article, "Home is Not A House," 32 argued that architecture, as exemplified by "houses" of history, is going to be replaced by machinery that takes care of temperature, air conditioning, communications, education, entertainment, etc. How this utopian vision of new technologies and materials can mediate lived existential meanings is the big question.

Arbib: Banham stated that the importance of François Dallegret's illustrations "demonstrate the hollowness of the fear of many architects that acceptance of the dominance of environmental machinery will be "the end of creativity'." The illustrations show naked people in a transparent environmental bubble with numerous "machines!"

Enns: Architecture-with-a-capital- $A$ is in a constant dance between technological change, cultural acceptance, and the filtered reflection of this culture (art). How does Cybernetic Architecture fit into this framework, and do established ideas about these relationships in architecture still apply (or are we somewhere new?) For me, Banham has always been the most helpful in clarifying Architecture's complex relationship with technology. ${ }^{33}$ Hassell: As a practice, we are evolving a new position for architecture based on systems thinking, incorporating many more systems than were incorporated in the twentieth century. Christopher Alexander's The Nature of Order (1981) refers to many of the relevant concepts. Jeremy Lent's The Patterning Instinct (2017) and Fritjof Capra's The Systems View of Life (2015) both help in formulating an approach to architecture which is regenerative and supportive of life and community rather than emphasizing consumerism and isolating the individual.

Macagno: To contribute to Baukultur as "essential for creating a built environment that is considered worth living in" ${ }^{34}$ the architect needs to address feelings, emotions, cognitive enhancement, aesthetic sense. This 
may justify offering the architect a "neuroscience toolkit" that may include devices that measure changes in heart rate, skin conductivity or pupil size, synchronized with recording of brain activity by means of EEG, fNIRS, $\mathrm{fMRI}$ and other techniques, in parallel with more subjective assays of experienced emotions and recalled memories.

These tools have been used to assay how specific architectural features yield different brain responses ${ }^{35}$ or how affordances affect users' emotional responses. ${ }^{36}$ While much work is currently done in virtual reality or in the controlled conditions of the laboratory, the expanding availability of multimodal wearable technologies will enable us to carry out more experiments in the real world, with its complex multisensorial stimuli. ${ }^{37}$ Ultimately, the more reductionist approach of the scientists needs to be extended to address the challenge of responding creatively to the realworld experience of the built/designed environment.

Hart: When I was studying architecture at Harvard (and reading Le Corbusier), Norbert Wiener was lecturing on cybernetics at MIT. Cybernetics, though, didn't have the technology it does today, nor did the human sciences, and the architectural mainstream drifted off into mind games. We didn't pay much attention to Richard Neutra (e.g., 1954) ${ }^{38}$ either until years later - and our Baukultur suffered. Instead, architecture, in our larger mainstream culture, has focused on "styles." I wonder if a kind of Chicago Manual of Style that spelled out the relationship between neuroscience and architecture - not a single style, of course, but what architectural styles have in common because of their human origins - could be produced to shed light on what's known about the researched responses of evolved human beings to specific characteristics of a built environment.

Arbib: There is no question that cybernetics will be a crucial component of future architecture. What is open to debate is the extent to which neuroscience's influence will be direct, based in part on redesign of computational models of biological brains, or indirect, filtered through Al techniques that have morphed as they have been adapted to advances in computers. For example, neuroscience models of supervised learning, Hebbian Learning and reinforcement learning were already in place in the mid-1990s, ${ }^{39}$ but it took immense leaps in computer speed and database size and conceptual adaptations to make "deep learning" ${ }^{40}$ the hallmark of the power of Al today. ${ }^{41}$

\section{BAUKULTUR, COMMUNITY \& BIOPHILIA}

Pallasmaa: Le Corbusier's "Machine for Living" and Arbib's "Neuromorphic Architecture," are both metaphors of architecture. I suggest that we need a third one, "Biophilic Architecture," referring to Edward O. Wilson's notion that our natural affinity for life - biophilia - is the very essence of our humanity and binds us to all other living species. ${ }^{42}$ I have no doubt that the biophilic future is grounded more on ethics than technology.

Arbib: Let us note, as a key dictum for Baukultur, the following quote from Kevin Roche: 
The most important thing one can achieve in any building is to get people to communicate with each other. That is really essential to our lives. We are not just individuals - we are part of a community. The old-time villages did that, and then we destroyed all that in the $19^{\text {th }}$ century, when we started to build these vast expansions where there was no center, there is no community. ${ }^{43}$

As an example of design with community and biophilia in mind, let us consider the Kampung Admiralty in Singapore (Figs. 3, 4), by the Singapore architecture firm WOHA, which was named the 2018 World Architecture Festival Building of the Year (Hassell is the HA of WOHA).

This is a "Vertical Kampung (village)," with a People's Plaza in the lower stratum, a Medical Centre in the mid stratum, and a Community Park with studio apartments for seniors in the upper stratum. ... The People's Plaza is a fully public, porous and pedestrianized ground plane, designed as a community living room, within which the public can participate in organized events, join in the season's festivities, shop, or eat at the hawker center on the second story. The breezy tropical plaza is shaded and sheltered by the Medical Centre above, allowing activities to continue regardless of rain or shine. Residents can actively come together to exercise, chat or tend community farms at the Community Park, an intimately-scaled, elevated village green "Buddy Benches" at shared entrances encourage seniors to come out of their homes and interact with their neighbors. ${ }^{44}$

There are hints of Singapore culture here (the hawker center for food) but overall, this provides a general twenty-first century solution for high density housing, replacing skyscrapers in which tenants are isolated from each other with buildings which foster both privacy and community within a green and inspiring environment. These residential complexes become linked through transit networks to those sites which give the city its culture(s). The cityscape must then preserve aspects of former glories while adding new buildings, parks, statues and urban complexes which in time may contribute both a shared sense of the city's history and areas where subcultures may flourish. Returning to my earlier theme, the overall city (and higher layers of government) must respect a principle of subsidiarity which supports the particularity of each culture while ensuring that the flourishing of each culture does not come at undue expense to others. (This is not to deny the possibility of conflict over balancing between divergent interests.)

Mallgrave: Kampung Admiralty is a wonderful example of biophilic design. The idea of terraced gardens accessible to people is far better than those placed on inaccessible "green" rooftops.

Hassell: Kampung Admiralty is designed as a node within as many systems as possible. It is a gateway to the mass rapid transit system, 


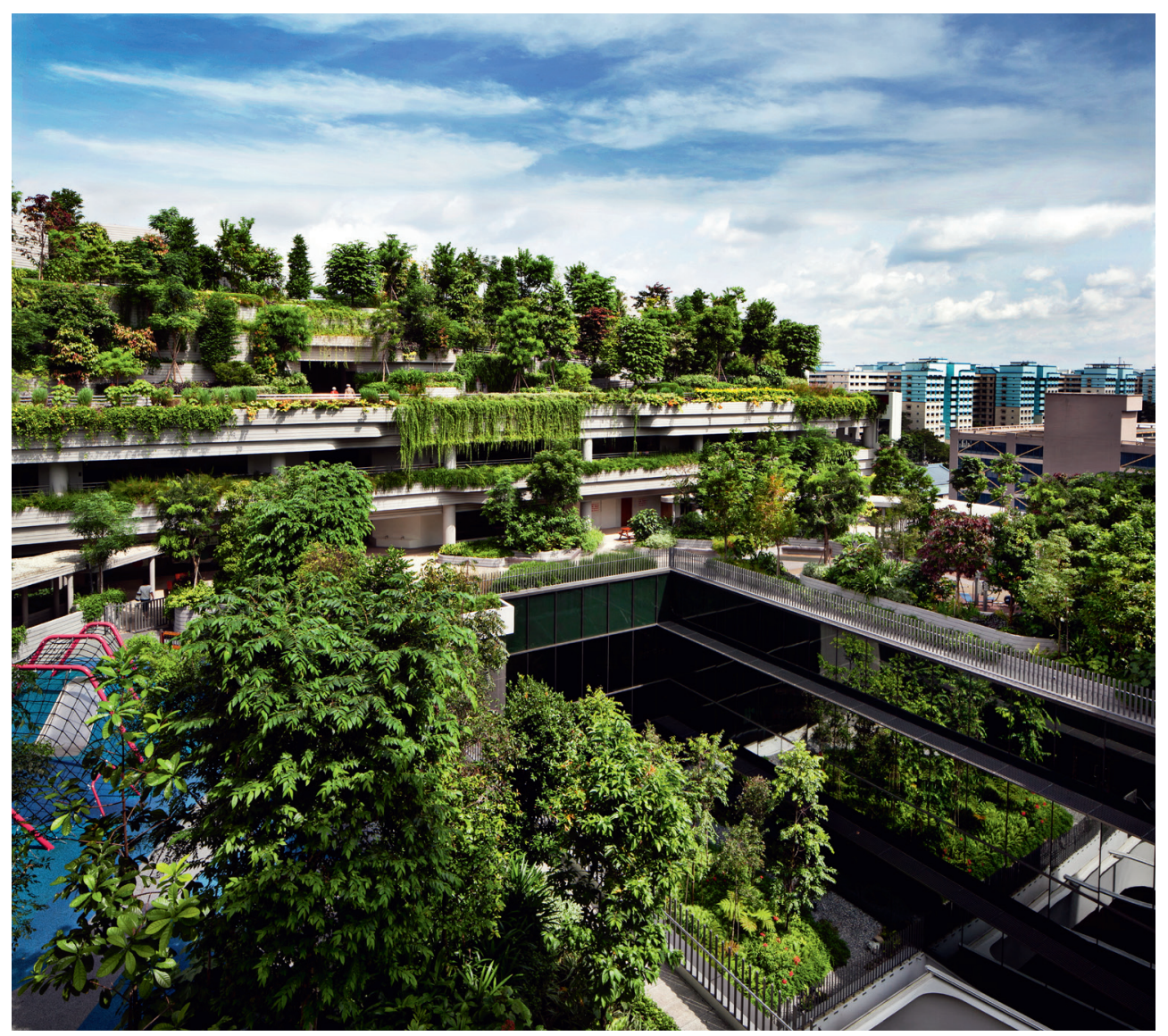

Figure 3. A view of WOHA's Kampung Admiralty from an interior vantage point.

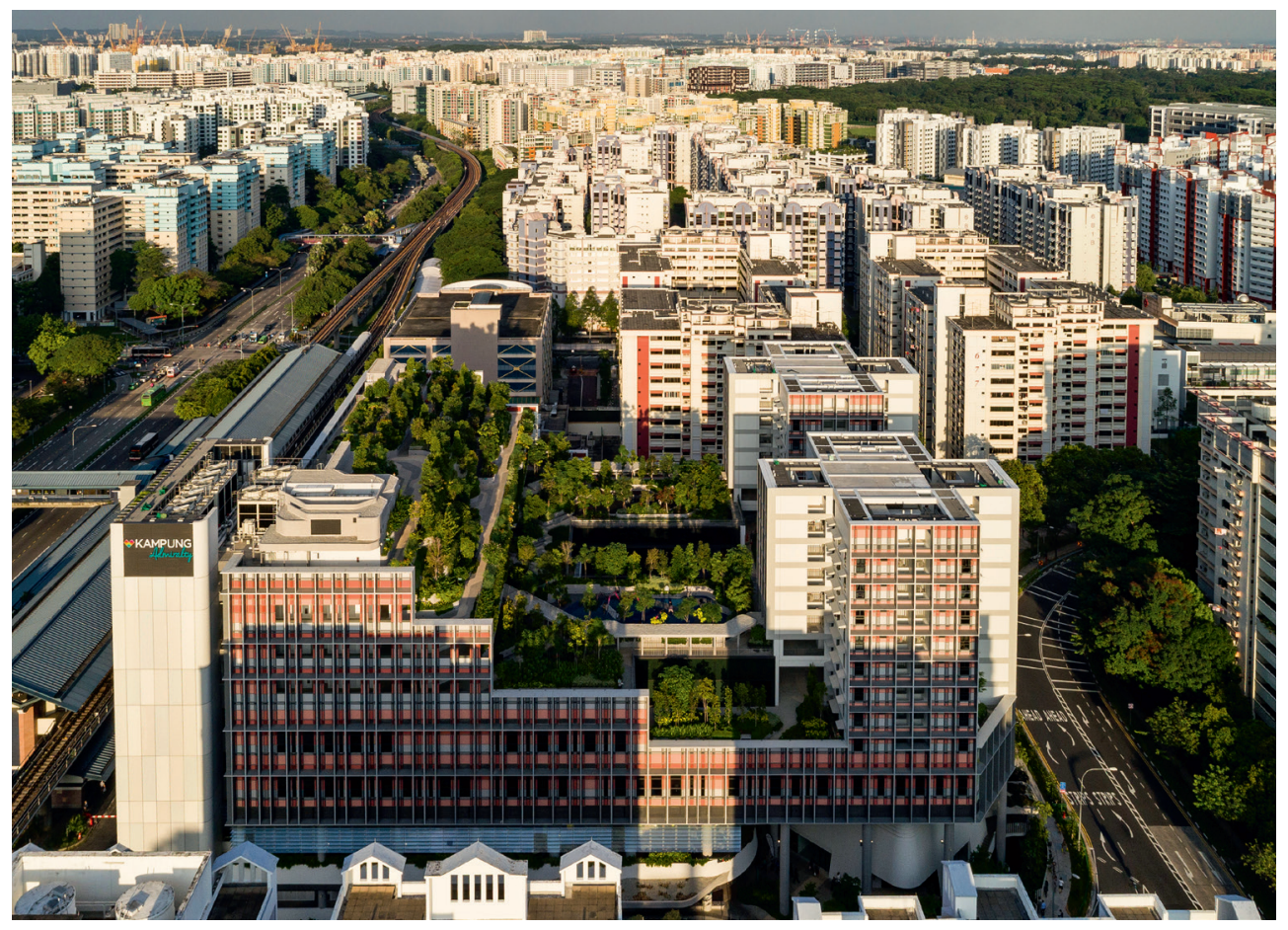

Figure 4. Kampung Admiralty viewed within the larger Singapore cityscape. 
and collects all the streets and footpaths nearby and guides pedestrian flow through the public spaces. The residential apartments add a new typology to the immense Singapore public housing system which houses $80 \%$ of the citizens. It brings together old patterns, such as the hawker center, with new patterns, such as a fully covered, breezy tropical plaza, which we felt were lacking in the hot tropical city. It has a public park on top, designed for biodiversity. The park is also a water collector and purifier, so it inserts itself as a regenerative system between the rain and the city's water system, circulating it multiple times internally through reed beds and its own irrigation systems before releasing it to the city system. The medical center is a node in the national medical system, and is a new typology, a neighborhood outlet that encourages life care rather than treatment. Childcare and elderly care are also nodes within the system, creating benefits to both groups through their adjacency. The elderly living there can access different urban modes on different floors - lively public space, noisy food center, caring medical center, fun activities at the center, quiet public park, community garden - all for free and without having to arrange transport. It was designed from ground up as a place for many social and infrastructural and natural systems to intersect, and through their intertwining, to create a whole greater than the sum of the parts for social and environmental benefits to emerge.

Ellard: Kampung Admiralty exhibits attributes that any good urban design should probably have wherever it is, but that can have an infinite number of instantiations and some of that variety is going to be driven by assessing what tradeoffs are and are not acceptable in the interests of particular subcultures.

Robinson: The quote by Roche brings out the vital point of the role of architecture in creating community. Rather than technological (including cybernetic) insertions, it seems that the most powerful role of design is ultimately configurative and concrete. The potential of the buddy benches in the Singapore project seem to me to be exemplary because they generate community in an innovative and concrete way. Can cybernetics really generate design conditions that would encourage community-oriented behavior? What would be the community/gathering analogue to the responsive kitchen, for example?

Arbib: Kampung Admiralty, with its system of systems approach, exemplifies an evolving Baukultur that combines cybernetic opportunities with a pioneering way that "community and biophilia" can be built into our cities. Architecture has long responded to the utilities of water and sewage, and gas and electricity, and has counted on urban services such as the orderly treatment of garbage and, increasingly recycling. The internet is beginning to transform not only the furnishings of our buildings but the way in which the dynamics of a building can respond in real time to the changing needs of its inhabitants. Nonetheless, humans are more than units in an ecologically sustainable ecosystem. We live, too, in a cultural world of language and art, of music and aesthetics, all of which combine to a shared sense of community in no sense limited to one street or apartment building. 
We must work toward an architecture that does not overly cocoon us, but creates an environment - the natural, the built, the social - in which each of us can thrive.

\section{Notes}

1. Michael A. Arbib, "Baukultur and Subsidiarity in a Cybernetic Age," Intertwining: Unfolding Art and Science 2 (2019): 62-79.

2. Davos Declaration 2018, "Towards a High-Quality Baukultur for Europe" (Davos, Switz.:

Conference of Ministers of Culture, 2018).

3. Richard Buday, "Persuasive Architecture," Texas Architect (Jan/Feb 2017): 53.

4. Emile G. Bruneau, "Putting Neuroscience to Work for Peace," in The Social Psychology of Intractable Conflicts, eds. Eran Halperin and Keren Sharvit (Cham, Switz.: Springer, 2015), 143-55.

5. Upali Nanda et al.,"Art and Posttraumatic Stress: A Review of the Empirical Literature on the Therapeutic Implications of Artwork for War Veterans With Posttraumatic Stress Disorder," Environment and Behavior 42, no. 3 (2010): 376-90, doi:10.1177/0013916510361874.

6. Kenneth Frampton, "Towards a Critical Regionalism: Six Points for an Architecture of Resistance," in The Anti-aesthetic: Essays on Post-modern Culture, ed. Hal Foster (Cambridge, UK: Cambridge University Press, 1983).

7. Le Corbusier, Towards a New Architecture, trans. from the thirteenth French edition, and intr., Frederick Etchells (London: John Rodker, 1927); also publ. as Toward an Architecture, transl. John Goodman, intr. Jean-Louis Cohen (Los Angeles: Getty Research Institute Publications Program, 2007); or. publ. as Vers une architecture (Paris: G. Crès, 1923).

8. Le Corbusier, Towards a New Architecture, 103.

9. Ibid.

10. Ibid., 108.

11. Ibid., 227

12. Ibid., 151.

13. Ibid., 217-81.

14. Le Corbusier, Toward an Architecture, 271.

15. James J. Gibson, The Ecological Approach to Visual Perception (Boston: Houghton Mifflin, 1979).

16. Davos Declartion 2018, "Towards a High-Quality Baukultur".

17. Michael A. Arbib, "Brains, Machines and Buildings: Towards a Neuromorphic Architecture," Intelligent Buildings International 4, no. 3 (2012): 147-68, doi:110.1080/17508975.17502012.1 7702863

18. Branko Kolarevic and Vera Parlac, eds. Building Dynamics: Exploring Architecture of Change (London and New York: Routledge, 2015).

19. Louis I. Kahn, "The Room, the Street, and Human Agreement," AIA Journal 56, no.3 (1971): 33-34.

20. Richard H. Thaler and Cass R. Sunstein, Nudge: Improving Decisions about Health, Wealth, and Happiness (New Haven CT, USA: Yale University Press, 2008).

21. A special issue of the New York Times Sunday Review (April 14, 2019) launched "The Privacy Project," https://www.nytimes.com/2019/04/10/opinion/privacy-project-launch.html. 22. Ibid.

23. Kynan Eng et al., "Design for a Brain Revisited: The Neuromorphic Design and Functionality of the Interactive Space 'Ada'," Reviews in the Neurosciences 14 (2003): 145. 24. James Graham Ballard (reprint), "The Thousand Dreams of Stellavista," in Vermilion Sands (New York: Berkley Books, 1971), https://arl.human.cornell.edu/linked\%20docs/ Ballard\%20Thousand\%20Dreams\%20of\%20Stellavista.pdf (Arbib thanks Branko Kolarevic for bringing this story to his attention.)

25. Arbib, Brains, Machines and Buildings.

26. Meredith Banasiak, "Neuroscience Laboratory Design: Understanding the Cognitive Processes of Neuroscientists at Work," workshop report (Dana Center, Washington DC, May 8 - 10, 2006), http://www.anfarch.org/wp-content/uploads/2020/01/ANFA-Wkshp_ Neuroscience-Laboratory-Design_Draft-2-transcript_July-2006.pdf. 
27. Stewart Brand, How Buildings Learn: What Happens after They're Built (New York: Penguin Books, 1995).

28. Mark Wilson, "Google Looks at the Mysterious Ways Design Influences How You Feel," Fast Company, March 25, 2019, https://www.fastcompany.com/90323347/googles-latest-petproject-uses-design-to-toy-with-your-brain; see also Susan Magsamen, "A Space for Being: A Neuroaesthetics Exhibit Featuring Design's Impact on Our Biology," The Academy of Neuroscience for Architecture, December 28, 2019, http://www.anfarch.org/a\%E2\%86\%94n17-a-space-for-being-a-neuroaesthetics-exhibit-featuring-designs-impact-on-our-biology/. 29. Juhan Sonin, "From Bathroom to Healthroom. How Magical Technology Will Revolutionize Human Health," Golnvo, https://www.goinvo.com/features/from-bathroom-tohealthroom/.

30. Richard Wener, "The Effectiveness of Direct Supervision Correctional Design and Management: A Review of the Literature," Criminal Justice \& Behavior 33 (June 2006): $392-$ 410.

31. Albert Borgmann, Technology and the Character of Contemporary Life: A Philosophical Inquiry (Chicago: University of Chicago Press, 1984).

32. Reyner Banham, "A Home Is Not a House," Art in America 2, no. 4 (1965).

33. Jared Langevin, "Reyner Banham: In Search of an Imageable, Invisible Architecture," Architectural Theory Review 16, no. 1 (2011): 2-21.

34. "About Baukultur," Bundesstiftung Baukultur, https://www.bundesstiftung-Baukultur.de/ en/about-Baukultur-1.

35. Maryam Banaei et al., "Walking through Architectural Spaces: The Impact of Interior Forms on Human Brain Dynamics," Frontiers in Human Neuroscience 11, no. 477 (2017), doi:10.3389/fnhum.2017.00477; Giovanni Vecchiato et al., "Electroencephalographic Correlates of Sensorimotor Integration and Embodiment during the Appreciation of Virtual Architectural Environments," Frontiers in Psychology 6 (1944), doi:10.3389/ fpsyg.2015.01944.

36. Zakaria Djebbara et al., "Sensorimotor Brain Dynamics Reflect Architectural Affordances," Proceedings of the National Academy of Sciences 116, no. 29 (2019): 1476978, doi:10.1073/pnas.1900648116.

37. Aashish N Patel Siddharth, Tzyy-Ping Jung, and Terrence J Sejnowski, "A Wearable Multi-Modal Bio-Sensing System Towards Real-World Applications," IEEE Transactions on Biomedical Engineering 66, no. 4 (2019): 1137-47, doi:10.1109/TBME.2018.2868759.

38. Richard J. Neutra, Survival through Design (New York: Oxford University Press, 1954). 39. Reviewed in various articles in Michael A. Arbib 1995 works. See Michael A. Arbib, ed., The Handbook of Brain Theory and Neural Networks (Cambridge MA, USA: A Bradford Book/The MIT Press, 1995).

40. Yann LeCun, Yoshua Bengio, and Geoffrey Hinton, "Deep Learning," Nature 521 (2015): 436-44, doi:10.1038/nature14539.

41. Bengio, Hinton and LeCun received the 2018 Turing Award for their breakthrough contributions: https://awards.acm.org/about/2018-turing.

42. Edward O. Wilson, Biophilia (Cambridge MA, USA: Harvard University Press, 1986). 43. Michael J. Crosbie, "Sitting Down with Kevin Roche: 'I Learned Everything I Know About Architecture from Eero'," ArchNewsNow, June 15, 2017, http://www.archnewsnow.com/ features/Feature512.htm.

44. Adapted from www.woha.net. WOHA's design philosophy was briefly described (with special thanks to Richard Hassell, the HA of WOHA) in Michael Arbib, "When Brains Design/Experience Buildings: Architectural Patterns for a Good Life," in Cultural Patterns and Neurocognitive Circuits: East-West Connections, eds. Jan W. Vasbinder and Balázs Z. Gulyás (Singapore: World Scientific, 2017), 111-40. The book by Patrick Bingham-Hall and WOHA Architects, Garden City Mega City (Singapore: Pesaro Publishing, 2016), presents WOHA's approach to rethinking architecture and cities for the twenty-first century. Disclosure: Richard's father is a cousin of Michael Arbib's wife. 


\section{References}

Arbib, Michael A., ed. The Handbook of Brain Theory and Neural Networks. Cambridge MA, USA: A Bradford Book/The MIT Press, 1995.

- - "Brains, Machines and Buildings: Towards a Neuromorphic Architecture." Intelligent Buildings International 4, no. 3 (2012): 147-68. doi:110.1080/17508975.17502012.17702 863.

- - . "When Brains Design/Experience Buildings: Architectural Patterns for a Good Life." In Cultural Patterns and Neurocognitive Circuits: East-West Connections, edited by Jan W. Vasbinder and Balázs Z. Gulyás, 111-40. Singapore: World Scientific, 2017.

- - . "Baukultur and Subsidiarity in a Cybernetic Age." Intertwining: Unfolding Art and Science 2 (2019): 62-79.

- - , ed. The Handbook of Brain Theory and Neural Networks. Cambridge MA, USA : A Bradford Book/The MIT Press, 1995.

Ballard, James Graham. "The Thousand Dreams of Stellavista," in Vermilion Sands (New York: Berkley Books, 1971). https://arl.human.cornell.edu/linked\%20docs/Ballard\%20 Thousand\%20Dreams\%20of\%20Stellavista.pdf.

Banaei, Maryam, Javad Hatami, Abbas Yazdanfar, and Klaus Gramann. "Walking through Architectural Spaces: The Impact of Interior Forms on Human Brain Dynamics." Frontiers in Human Neuroscience 11, no. 477 (2017). doi:10.3389/fnhum.2017.00477.

Banham, Reyner. "A home is not a house." Art in America 2, no. 4 (1965).

Bingham-Hall, Patrick, and WOHA Architects. Garden City Mega City. Singapore: Pesaro Publishing, 2016.

Borgmann, Albert. Technology and the Character of Contemporary Life: A Philosophical Inquiry. Chicago: University of Chicago Press, 1984.

Brand, Stewart. How Buildings Learn: What Happens after They're Built. New York: Penguin Books, 1995.

Bruneau, Emile G. "Putting Neuroscience to Work for Peace." In The Social Psychology of Intractable Conflicts, edited by Eran Halperin and Keren Sharvit, 143-55. Cham, Switz:: Springer, 2015.

Buday, Richard. "Persuasive Architecture." Texas Architect (Jan/Feb 2017): 53.

Catania, Kenneth C., and Jon H. Kaas. "The Unusual Nose and Brain of the Star-Nosed Mole." BioScience 46, no. 8 (1996): 578-86.

Davos Declaration 2018. "Towards a High-Quality Baukultur for Europe." Davos, Switz.: Conference of Ministers of Culture, 2018a.

- - . "Towards a High-Quality Baukultur for Europe: Context Document." Davos, Switz.: Conference of Ministers of Culture, 2018b.

Djebbara, Zakaria, Lars Brorson Fich, Laura Petrini, and Klaus Gramann. "Sensorimotor Brain Dynamics Reflect Architectural Affordances." Proceedings of the National Academy of Sciences 116, no. 29 (2019): 14769-78. doi:10.1073/pnas.1900648116.

Eng, Kynan, David Klein, Andreas Bäbler, Ulysses Bernardet, Mark Blanchard, Marcio Costa, Tobi Delbrück, et al. "Design for a Brain Revisited: The Neuromorphic Design and Functionality of the Interactive Space 'Ada'," Reviews in the Neurosciences 14 (2003): 145.

Gibson, James J. The Ecological Approach to Visual Perception. Boston: Houghton Mifflin, 1979.

Kahn, Louis I. "The Room, the Street, and Human Agreement." AIA Journal 56, no. 3 (1971): 33-34.

Kolarevic, Branko and Vera Parlac, eds. Building Dynamics: Exploring Architecture of Change. London and New York: Routledge, 2015.

Langevin, Jared. "Reyner Banham: In Search of an Imageable, Invisible Architecture." Architectural Theory Review 16, no. 1 (2011): 2-21.

Le Corbusier. Towards a New Architecture. Translated from the thirteenth French edition, and with an introduction by Frederick Etchells. London: John Rodker, 1927. Also publ. as Toward an Architecture. Translated by John Goodman with an introduction by Jean-Louis Cohen. Los Angeles: Getty Research Institute Publications Program, 2007. Or. publ. as Vers une architecture. Paris: G. Crès, 1923. 
LeCun, Yann, Yoshua Bengio, and Geoffrey Hinton. "Deep Learning," Nature 521 (2015): 436-44. doi:10.1038/nature14539.

Nanda, Upali, H. Lea Barbato Gaydos, Kathy Hathorn, and Nicholas Watkins. "Art and Posttraumatic Stress: A Review of the Empirical Literature on the Therapeutic Implications of Artwork for War Veterans With Posttraumatic Stress Disorder." Environment and Behavior 42, no. 3 (2010): 376-90. doi:10.1177/0013916510361874.

Neutra, Richard J. Survival through Design. New York: Oxford University Press, 1954.

Siddarth, Aashish N Patel, Tzyy-Ping Jung, and Terrence J Sejnowski. "A Wearable Multi-Modal Bio-Sensing System Towards Real-World Applications." IEEE Transactions on Biomedical Engineering 66, no. 4 (2019): 1137-47. doi:10.1109/TBME.2018.2868759.

Thaler, Richard H., and Cass R. Sunstein. Nudge: Improving Decisions about Health, Wealth, and Happiness. New Haven CT, USA: Yale University Press, 2008.

Vecchiato, Giovanni, Gaetano Tieri, Andrea Jelic, Federico De Matteis, Anton G. Maglione, and Fabio Babiloni. "Electroencephalographic Correlates of Sensorimotor Integration and Embodiment during the Appreciation of Virtual Architectural Environments." Frontiers in Psychology 6 (1944). doi:10.3389/fpsyg.2015.01944.

Wener, Richard. "The Effectiveness of Direct Supervision Correctional Design and Management: A Review of the Literature." Criminal Justice \& Behavior 33 (June 2006): 392-410.

Wilson, Edward O. Wilson, Biophilia. Cambridge MA, USA: Harvard University Press, 1986.

\section{Acknowledgments}

Arbib thanks Sarah Robinson for inviting him to write the core article for Intertwining, and the co-authors of this conversation for all they have contributed in opening up the themes of the original article. That article was based in part on work supported by the National Science Foundation under Grant No. BCS-1343544 "INSPIRE Track 1: Action, Vision and Language, and their Brain Mechanisms in Evolutionary Relationship."

\section{Credits}

Figure 1: image retrieved from Kenneth C. Catania and Jon H. Kaas, "The Unusual Nose and Brain of the Star-Nosed Mole," BioScience 46, no. 8 (1996): 578-586. Images at left courtesy of Kenneth Catania.

Figure 2: image courtesy of Rodney Douglas.

Figure 3: courtesy of Richard Hassell; photo by Patrick Bingham-Hall.

Figure 4: courtesy of Richard Hassell; photo by Lim Weixiang. 
Michael A. Arbib is an Adjunct Professor of Psychology at the University of California, San Diego and University Professor Emeritus at the University of Southern California. He was founding Coordinator of the ANFA Advisory Council. His first book was Brains, Machines, and Mathematics [1964]; his current concern linking neuroscience to the experience and design of architecture, and neuromorphic architecture - supplying buildings with "brains" is the subject of his 2021 book When Brains Meet Buildings: A Conversation Between Neuroscience and Architecture. E-mail: arbib@usc.edu

Meredith Banasiak is a Senior Instructor, Community Engagement Design and Research Center at the University of Colorado, Boulder. E-mail: meredithbanasiak@yahoo.com

Robert Condia is a Professor of Architecture at Kansas State University. E-mail: rcondia@k-state.edu

Colin Ellard is a Professor of Psychology at the University of Waterloo.

E-mail: cellard@uwaterloo.ca

Jonathan Enns is an Assistant Professor of Architecture at the University of Waterloo.

E-mail: jonathan.enns@uwaterloo.ca

Melissa Farling, FAIA, is a principal of Gould Evans, Phoenix studio.

E-mail: melissa.farling@gouldevans.com

Robert Lamb Hart is an architect and author of A New Look at Humanism - in Architecture, Landscapes and Urban Design. E-mail: bhart2007@gmail.com

Richard Hassell is a key architect and co-founder, WOHA, Singapore.

E-mail: rwhassell@gmail.com

Eduardo Macagno is a neuroscientist and Distinguished Professor at UC San Diego.

E-mail: emacagno@ucsd.edu

Harry Mallgrave is Distinguished Professor Emeritus, Illinois Institute of Technology, and an Honorary Fellow of the Royal Institute of British Architects. E-mail: mallgrave@iit.edu

Fred Marks is a Visiting Scholar at the Salk Institute for Biological Studies.

E-mail: fmmarks@aol.com

Juhani Pallasmaa is an architect, author, and Professor Emeritus at Aalto University, Helsinki. E-mail: jpallasmaa@gmail.com

Sarah Robinson is an architect and writer in Pavia, Italy. E-mail: sarah @srarchitect.com 